\title{
ANATOMIA DA CORRUPÇÃO TRANSNACIONAL: DESVENDANDO AS TEIAS E TRILHAS DO DINHEIRO SUJO EM NEGÓCIOS LEGÍTIMOS
}

Cintia Rodrigues de Oliveira ${ }^{1}$ e Isabella Chaves do Nascimento

Universidade Federal de Uberlândia - UFU, Uberlândia, Minas Gerais, (Brasil)

\section{DETALHES DO ARTIGO}

\section{Histórico do Artigo:}

Recebido em: 09 de Abril de 2020

Aceito: 30 de Novembro de 2020

Disponível online: 01 de janeiro de 2021

\section{Sistema de revisão "Double blind review"}

\section{Editor Científico}

Ilan Avrichir

\section{Palavras-chaves:}

Corrupção transnacional

Bancos

Crime

\begin{abstract}
RESUMO
Objetivo: Examinar a corrupção transnacional a partir de observações empíricas coletadas do setor bancário, mais especificamente, de um dos maiores bancos internacionais, o HSBC.
\end{abstract}

\begin{abstract}
Método: Pesquisa qualitativa, do tipo documental, com a análise de reportagens, dos últimos dez anos, sobre casos de corrupção envolvendo um dos maiores bancos internacionais do mundo. Utilizou-se a codificação aberta pelo modelo temático.
\end{abstract}

Principais resultados - Os resultados apontam para as trilhas da corrupção, as redes de atores e envolvidos, e os esquemas de corrupção.

\begin{abstract}
Relevância/originalidade - A corrupção é um tema atual e relevante, porém, a maioria das análises consideram o lado da demanda, e não o da oferta na equação da corrupção global. Além disso, esta pesquisa aborda a corrupção como um fenômeno transnacional e não local.
\end{abstract}

Contribuições teóricas/metodológicas: Necessário - Este estudo contribui pela abordagem teórico-metodológica, pois aborda um fenômeno em um contexto internacional, cujo acesso a dados consiste em um obstáculo, pois é improvável que esquemas e operações entre funcionários corruptos sejam passíveis de exibição pública, a menos que os casos sejam expostos na imprensa ou estejam sob investigação.

Contribuições sociais / para a gestão: A pesquisa contribui para que gestores de companhias com alcance local e internacional, tenham entendimento mais amplo das consequências do envolvimento em operações e ligações perigosas.

\section{Introdução}

A corrupção, com um custo econômico estimado em trilhões de dólares, em âmbito mundial, acarreta ainda um custo humano devastador, matando e levando milhões de pessoas à pobreza em países em desenvolvimento, falindo estados e gerando terrorismo e ameaça à segurança nacional em diversos países do mundo (Global Witness, 2015). Considerada um crime contra a humanidade (Banketas, 2006), a corrupção ocorre na interseção de agentes criminosos e negócios legítimos, não se resumindo a um fenômeno local, e, assim como o crime organizado ou o terrorismo transnacional, suas ações ultrapassam fronteiras, sendo uma das mais sérias e complexas atividades criminais que impactam os países em desenvolvimento (Ware \& Noone, 2005).

A organização Transparency International, um movimento global criado com a finalidade de acabar com a corrupção no mundo, expondo os sistemas e redes que facilitam a perpetuação da corrupção, realizou uma pesquisa relativa a 2017, indicando que a maioria dos países não evoluiu no combate a corrupção, o que resulta em uma média global de 43 pontos, o que também revela corrupção endêmica no setor público. Como em outros anos, a região com melhor desempenho foi a Europa Ocidental (média de 66 pontos) e as de pior resultado, a África Subsaariana (média de 32 pontos) e a Europa Oriental

\footnotetext{
${ }^{1}$ Contato do autor - Email: cintia@ufu.br
}

DOI: 10.18568/internext.v16i1.603 
e Ásia Central (média de 34 pontos) (Transparency International, 2018). Um aspecto a considerar, e tomando como ponto de partida a crítica de Avritzer et al. (2012) sobre a necessidade de se discutir a atuação de outros agentes que não do setor público, é que os esquemas de corrupção se desenvolvem com a participação estrangeira no lado da oferta da equação da corrupção.

Entre outros exemplos, destacam-se: o esquema envolvendo a multinacional alemã Siemens, além de outras empresas de tecnologia e o metrô de São Paulo, que veio à tona em 2013, revelando o pagamento de propina referente a uma concorrência de 2002 para um contrato de manutenção (Gallas, 2013); o "Fifagate", nome com o qual ficou conhecido o maior escândalo de corrupção da história do futebol (El Pais, 2015), investigado nos EUA, que envolve bancos estadunidenses, autoridades suíças; paraísos fiscais, como a Suíça, também se tornariam um escândalo em 2015, com a divulgação de dados vazados de clientes do HSBC Private Bank Swiss por um funcionário (Ryle, et al., 2015b).

Linstead, Maréchal e Griffin (2014) argumentam que a corrupção faz parte do lado sombrio das organizações, e, como tal, precisa ser compreendida não apenas em termos de consequências não intencionais ou não conformidades rotineiras, mas, sim, como atitudes deliberadas, conscientes e intencionais em busca de interesses específicos. Novos quadros teóricos, com as teorias críticas, podem facilitar a "desfamiliarização" de antigos fenômenos organizacionais, permitindo ampliar sua compreensão ou mesmo desvelar partes ocultas.

A possibilidade de contribuição teórica para os estudos organizacionais sobre corrupção transnacional se dá pela utilização de uma abordagem distinta da versão funcionalista recorrente nas ciências sociais (Lambsdorff; Schulze, 2015), visto que utilizamos uma abordagem que permite compreender como esse fenômeno opera, o que não foi encontrado no campo dos estudos organizacionais brasileiros, conforme pesquisa realizada nos portais Scientific Periodicals Eletronic Library (SPELL - Biblioteca Eletrônica de Periódicos Científicos) e da Associação Nacional de PósGraduação em Administração (ANPAD),em pesquisa realizada em 2018. Em ambos os casos, não foi encontrada nenhuma pesquisa com esta proposta, o que consideramos um ponto de partida para que possamos trazer não apenas mais profundidade, mas, também, um novo olhar para essa temática de pesquisa. Adicionalmente, a revisão bibliográfica sobre corrupção e negócios internacionais realizada por Bahoo, Alon e Paltrinieri (2020) apontou a baixa produção internacional sobre corrupção internacional.

Neste artigo, nosso objetivo é examinar a corrupção transnacional a partir de observações empíricas coletadas do setor bancário, mais especificamente, de um dos maiores bancos internacionais, o HSBC, acrônimo do inglês Hong Kong and Shanghai Banking Corporation. Buscando oferecer uma visão abrangente da corrupção transnacional, considerando os lados da oferta e demanda, nós analisamos informações divulgadas em documentos públicos e utilizamos a codificação temática, em sua abordagem qualitativa, como recurso metodológico. Os documentos analisados foram extraídos da imprensa internacional quando essa reportava escândalos que vieram à tona, com o Panama Papers e Swiss Leaks. O artigo está estruturado da seguinte forma: depois desta introdução, apresentamos a revisão da literatura sobre corrupção transnacional; em seguida, descrevemos os procedimentos da pesquisa, os resultados e, por fim, as considerações finais.

\section{Corrupção Transnacional: esquemas, atores e mecanismos}

Corrupção e crime global estão intimamente conectados, visto que contrabando, tráfico de armas e drogas, lavagem de dinheiro, terrorismo e tantos outros seriam impraticáveis sem o envolvimento de funcionários corruptos nas alfândegas, agências financeiras, prestadores de serviço ou policiais. Pelas características de ameaça à segurança e desrespeito às fronteiras, a corrupção e o crime se tornaram objetos de medidas internacionais de controle e mitigação. Governos recebem incentivos para se engajarem nessa luta, como empréstimos a um custo menor, melhores ratings (avaliações) de crédito e promessas de entrada em organismos internacionais, bem como condicionalidades ou, até mesmo, sanções por negligenciarem as orientações dos acordos (Christensen, 2011).

A corrupção é um tema multidisciplinar, sendo definida por diferentes perspectivas. Nesta pesquisa, nós concordamos com a definição de Bahoo, Alon e 
Anatomia da corrupção transnacional: Desvendando as teias e trilhas do dinheiro sujo em negócios legítimos

Paltrinieri (2020) quanto a três características que o termo carrega: a realização de uma atividade ilegal; mau uso do poder ou autoridade em violação das regras e regulamentos existentes ou além dos limites legais; uso de uma posição de poder para obter benefícios pessoais (financeiros ou não).

Heimann e Boswell (1998) distinguem as origens da corrupção pelo lado da demanda (os destinatários do suborno ou corrompidos), geralmente associado à esfera pública; e pelo lado da oferta (doadores do suborno ou corruptores), geralmente associado à esfera privada. $\mathrm{O}$ argumento de que corrupção transnacional é particularmente insidiosa nos países em desenvolvimento, onde ocorre de forma massiva e sistemática e para os quais a ajuda internacional e os fundos para desenvolvimento poderiam representar um alívio (Ware, \& Noone, 2005). Entretanto, Harvey (2020) considera que a corrupção não é um grande problema global que impacta negativamente o desenvolvimento de um grande número de países mais pobres, mas, sim, reconhece que a corrupção é um problema tanto para os países onde os fundos são investidos como, também, para os estados vítimas da corrupção.

A Transnational Organised Crime Convention de 2000 definiu Corrupção Transnacional como a corrupção (ativa e passiva) em que três aspectos são encontrados: envolvimento de uma organização ou grupo criminoso; existência de, pelo menos, um elemento transnacional; e o ato corrupto que acontece nessas circunstâncias (Basteskas, 2006). Esse tipo de corrupção, diferenciando-se do tipo local pela magnitude, complexidade e impunidade dos participantes (Sung, 2009), é a corrupção que cruza as fronteiras, envolve agentes corporativos e governamentais que, por meio de sofisticados esquemas, drenam as riquezas dos países aos quais deveriam servir. Independentemente do país ou da cultura, observam-se que os mecanismos da corrupção transnacional têm formas muito similares de atuação (Sung, 2005; Ware, \& Noone, 2005).

Empresas multinacionais pagam propinas para obter tratamento preferencial em contratos, concessões e acordos de privatizações. Os benefícios podem consistir na própria adjudicação do contrato ou em informações privilegiadas que tornam o êxito mais provável e, ainda, em alterações nos termos dos contratos ou no ambiente regulatório futuro. Mesmo quando as empresas acreditam que têm uma forte chance de vencer uma concorrência honesta, elas podem se submeter a negociatas, acreditando que os riscos de sanções legais e danos à reputação são compensados pelos valores envolvidos. Grandes corporações apoiariam os esforços internacionais anticorrupção se a situação global pudesse ser descrita como um jogo de coordenação, no qual os pagamentos de suborno individual maximizam o lucro dos jogadores no contexto empresarial atual; no entanto, se a corrupção fosse eliminada, todas as empresas se beneficiariam e nenhuma teria um incentivo para se desertar unilateralmente (RoseAckerman, 2002).

Com o intuito de ampliar a compreensão sobre a corrupção transnacional, Ware e Noone (2005) sugerem uma possível anatomia comum do fenômeno nos países em desenvolvimento, independentemente da sua ocorrência na África, Oriente Médio, Ásia ou América Latina. Os autores descrevem seis esquemas repetidamente empregados pelos corruptores, globalmente, sendo eles: pagamento de propinas, utilização de operadores (brokers), empresas de fachada, estabelecimento de cartéis para fraudar licitações públicas, utilização de empresas de familiares do governo e, diretamente, fraude de contas do governo e abuso de bens públicos.

A existência de um sistema de incentivo ao comportamento antiético e criminal no setor financeiro baseado em remunerações e bonificações é observado indiretamente em diversas questões e, particularmente, naquela que descreve que "quase um terço dos entrevistados (32\%) acredita que as estruturas de compensação ou os planos de bônus em vigor em sua empresa poderiam incentivar os funcionários a comprometer a ética ou violar a lei" (Tenbrunsel, \& Thomas, 2015, p.3). Bahoo, Alon e Paltrinieri (2020) encontraram em uma extensa revisão da literatura que decisões dos gerentes de se envolverem com corrupção resultam em problemas de agência, no entanto, os gerentes argumentam que elas são benéficas para a empresa.

Apesar dos esforços desenvolvidos pela comunidade internacional, conspirações corruptas continuarão ocorrendo onde existirem controles inadequados, legislação insuficiente, e regimes insatisfatórios de compliance, podendo essas serem reduzidas, na maioria dos casos, a uma "questão de oportunidade e ganância" (Ware, \& Noone, 2005, p.44). É conhecido pelas autoridades que agentes do sistema financeiro global assumem, rotineiramente, 
riscos éticos e financeiros, visto a quantidade considerável de pesquisas nos últimos anos, indicando que bancos admitem ter ignorado ou contornado os regimes de combate à corrupção e à lavagem de dinheiro (Platt, 2017).

Diversos intermediários no sistema financeiro operam para viabilizar a corrupção transnacional, uma vez que, normalmente, negociações não se restringem a apenas duas partes. Os intermediários, na maioria dessas transações, não são criminosos, mas, sim, empresas e atores legítimos que prestam serviços remunerados, como banqueiros, advogados, contadores e corretores de imóveis, os quais direcionam os saques da corrupção para bancos e propriedades de luxo. Nesse contexto, quatro canais principais podem ser identificados na lavagem do dinheiro da grand corrupção: os bancos, as empresas de fachada, o mercado de imóveis estrangeiros e os programas de dupla cidadania ou vistos de investidores (Cooley, \& Sharman, 2017).

Apesar de pouco explorados nos estudos sobre corrupção, os intermediários são essenciais nessa dinâmica, pois eles são os responsáveis por diluir os custos de transação (Cooley, \& Sharman, 2017), conforme o argumento sustentado no conceito de "Cadeias Globais de Riqueza" ilícitas (Seabrooke \& Wigan, 2017). Nessa lógica, ao invés do processo de produção, tem-se a gestão da riqueza e, no lugar da eficiência, o objetivo principal das Cadeias Globais de Riqueza é evitar a responsabilização, entendida como reivindicações fiscais, obrigações legais ou supervisão regulatória ou vantagens garantidas em virtude de sua localização, prioritariamente, em paraísos fiscais.

As definições de paraíso fiscal estão associadas a lugares que oferecem facilidades que vão além de otimização de impostos e convenções políticas, permitindo que não exista um consenso nas listas de jurisdições com essa classificação (Tax Justice Network, 2018); um conjunto de atividades e serviços oferecidos a indivíduos e empresas relativos a oportunidades favoráveis de otimização fiscal, confidencialidade, legislação e regulamentação que, não necessariamente, são criminosas (Platt, 2017); jurisdições que fornecem recursos a pessoas ou entidades, permitindo que escapem das leis, regras e regulamentos de outras jurisdições, utilizando o sigilo como uma ferramenta primordial (Tax Justice Network, 2018). A terminologia offshore é normalmente utilizada para se referir aos paraísos fiscais, apesar de serviços equivalentes existirem em jurisdições onshore, como nos exemplos do Reino Unido, dos EUA e da Suíça (Platt, 2017).

A relevância da discussão sobre o papel dos intermediários reside no sentido de questionar a dicotomia convencional de países ricos e honestos versus os pobres e corruptos e, ao mesmo tempo, compreender que não existe uma separação estrita entre economias ilícitas e lícitas. Além disso, existe um movimento de globalização dos indivíduos envolvidos na grand corrupção, como a aquisição de dupla cidadania, por exemplo, dissociando-os intencionalmente de seus estados de origem para proteger sua atuação e sua fortuna (Cooley, \& Sharman, 2017).

No contexto de redes transnacionais, são particularmente problemáticas e comuns as falhas de instituições financeiras na identificação de grupos de risco (Politically Exposed Person -PEP), os quais exigem maior diligência (Cooley, \& Sharman, 2015, 2017), como os detentores de cargos públicos, seus familiares e sócios, bem como clientes corporativos que, pela natureza ou localização das suas operações, têm maior probabilidade de se envolverem em subornos. A identificação desses atores deveria desencadear um procedimento de avaliação de risco de corrupção imediato e continuado, mas a realidade observada tem sido bem diferente (Platt, 2017; STAR, 2009).

Lasslet (2017) aplicou um framework para investigação de corrupção em um caso de grande corrupção. O caso trata-se de um projeto liderado pela Austrália, na capital de Papua Nova Guiné, Port Moresby. A pesquisa apontou, além das características locais no esquema de corrupção, uma rede transnacional de atores envolvidos no poder corporativo do estado, a ambiguidade da sociedade civil e as desigualdades estruturais que minam com os movimentos de resistência. A análise considerou as categorias: os nós (atores); laços (relações); e as transações, que são os elementos mais básicos de esquemas de corrupção. Adicionalmente, o framework foi composto por unidades mais avançadas de análise que permitiram capturar elementos das estruturas e processos: arquitetura de rede, sequência de transações, biografias dos atores e repertórios comerciais/políticos, as motivações, estruturas de oportunidade e culturas de conformidade que sustentam as especificidades regionais. $O$ estudo relevou que a atividade transnacional envolveu formas complexas de 
Anatomia da corrupção transnacional: Desvendando as teias e trilhas do dinheiro sujo em negócios legítimos

manipulação regulatória e de mercado, as quais foram pensadas para extrair altos lucros.

No campo corporativo, conduzir due diligence de empresas, fundações e associações para as quais se presta serviço também é um padrão internacional obrigatório para instituições financeiras, estando previsto nas recomendações contra a lavagem de dinheiro emitidas pelo Financial Action Task Force (FATF - Grupo de Ação Financeira Internacional), que são consideravelmente negligenciadas, visto os indícios de que apenas uma pequena parte do dinheiro ilegal que passa pelos bancos seja efetivamente identificada como tal, apesar de todos os requerimentos legais em contrário (STAR, 2011). Na mesma perspectiva das PEPs, o acompanhamento deveria se iniciar na identificação do(s) proprietário(s) beneficiário(s), quando a relação de negócio se estabelece, e continuar durante todo seu ciclo de vida, o que é justificado pela complexidade que se espera na ocultação do verdadeiro propósito em um relacionamento comercial de longo prazo (STAR, 2011).

As revelações contidas no Panama Papers, em 2016, demonstraram como se dá o funcionamento desses canais de lavagem de dinheiro por meio de intermediários, como o escritório de advocacia Mossack \& Fonseca, proporcionando aos clientes proteções importantes, como os direitos à privacidade e à segurança da propriedade (Cooley, \& Sharman, 2017), mesmo com todas as convenções e regulamentações internacionais em contrário. Nos documentos, é possível observar que, entre os mais de 500 bancos contratantes de serviços, os mais importantes se localizavam na Suíça, no Reino Unido e em Luxemburgo, e os maiores mercados para as empresas de fachada eram a China, a Rússia e a América Latina, sendo os produtos mais contratados aqueles associados às Ilhas Virgens Britânicas (113.648), seguidos, de longe, pelo próprio Panamá (48.360) (ICIJ, 2017).

\section{Procedimentos Metodológicos}

Esta pesquisa é de natureza qualitativa e o método de procedimento é a pesquisa documental, cujas fontes são secundárias, extraídas de jornais eletrônicos e do website do banco protagonista do estudo. Considerando que a realidade social pode ser representada em comunicações formais ou informais (Flick, 2009), nossa opção pela análise de reportagens de jornais parte da compreensão de que comunicações formais reconstroem maneiras pelas quais a realidade social pode ser representada por grupos de interesse e, sendo assim, carregam em si a visão de mundo de um determinado público.

A construção do corpus de pesquisa implica na escolha sistemática, invariavelmente arbitrária, para seleção de representações significantes do contexto a ser analisado (Bauer e Aarts, 2002). Os critérios para seleção foram: análise de uma organização multinacional do setor bancário, o que permite o encontro com nosso contexto de corrupção transnacional; envolvimento com casos de corrupção nos últimos 10 anos, mesmo não sendo a organização o principal agente, pois esse quesito implica na disponibilização de material documental para a investigação.

A partir desses critérios, analisamos a lista cronológica de exemplos de bancos indiciados e processados desde a década de 1990 até 2015, a qual consta do relatório Banks and Dirt Money, da organização não governamental Global Witness (2015, p.11), que identifica, nominalmente, dezenove instituições, entre as quais o HSBC aparece com o maior número de ocorrências. Esse banco britânico, além de um dos maiores bancos internacionais em ativos (S\&P, 2017), teve participação em grandes escândalos de fraudes e crimes financeiros, destacando-se os seguintes casos conhecidos: a maior multa aplicada a um agente individual por lavagem de dinheiro, em 2012 (DOJ, 2012); o maior vazamento de dados bancários da história, que se refere à filial suíça, divulgado ao público em 2015 pelo Swiss Leaks (Ryle et al., 2015); e o envolvimento com o escritório Mossack \& Fonseca, seu principal cliente bancário, no maior vazamento de informações de contas offshore divulgado, em 2016, pelo Panama Papers (ICIJ, 2016).

Para a seleção do corpus de pesquisa, consideramos que esses e outros eventos envolvendo o HSBC foram amplamente noticiados em diversos jornais em todo o mundo. Entretanto, cientes que o tamanho do corpus deve considerar o equilíbrio entre o esforço envolvido na coleta e análise de dados, bem como o número de representações que se desejam caracterizar (Bauer, \& Aarts, 2002), restringimos as fontes da pesquisa documental pelos critérios de cobertura jornalística de livre acesso/ gratuita, internacionalmente reconhecida e com protagonismo jornalístico em 
algum dos casos envolvendo o HSBC: o International Consortium of Investigative Journalists (ICIJ) e o jornal britânico The Guardian.

A seleção dessas fontes levou em consideração a constituição do IClJ por se tratar de um consórcio internacional reconhecido e ter sido responsável pela realização e publicação das séries de reportagens que ficariam conhecidas como Swiss Leaks, um vazamento sem precedente na história bancária (Ryle, et al., 2015a). A escolha do The Guardian foi ponderada por duas questões: o fato de ser um jornal do Reino Unido, assim como o HSBC, bem como pela sua credibilidade como fonte, sendo considerado como o principal jornal britânico (4IMN, 2017). Os textos estão originalmente em inglês e foram analisados nesse idioma, sendo apresentados em português nas seções de resultados e discussões com tradução nossa.

A coleta de documentos ocorreu, inicialmente, pelo conjunto das reportagens divulgadas em 2015, as quais estavam associadas ao vazamento dos dados da filial suíça do HSBC, no ICIJ, conhecido como a investigação SwissLeaks (16), e, no The Guardian, como um conjunto de reportagens em cinco partes, chamada de HSBC files (18). Posteriormente, realizamos três consultas adicionais em cada um dos dois websites, utilizando as palavras-chave de busca: "HSBC corruption", "HSBC corrupt" e "HSBC bribery". A partir dos web links de reportagens indicadas nas seis consultas desta etapa, foram desconsideradas as repetições e catalogados mais 93 documentos. A partir dessa base, foi realizada uma primeira leitura para identificação da aderência ao conteúdo, especificamente, se havia relatados da participação do HSBC, seus agentes, clientes ou pares do sistema financeiro em casos envolvendo práticas de corrupção. Como critérios de exclusão foram considerados: textos que incluíam apenas a citação do nome do banco em outro contexto; textos que não continham nenhuma das palavras-chave utilizadas para referência à corrupção; e reportagens do tipo opiniões e blogs. Assim, em conjunto com o material da primeira etapa, foram selecionados 55 textos (12 ICIJ e 43 The Guardian) publicados de 11 de março de 2009 a 15 de janeiro de 2018. O material empírico foi tratado visando à padronização, tendo resultado em 208 laudas, as quais foram analisadas com o suporte do software Atlas TI, v.8, para, a partir da organização das fontes e da leitura flutuante, proceder à codificação aberta pelo modelo temático (Flick, 2009). Na codificação aberta, o material empírico foi analisado em fragmentos menores, frase a frase, sendo cada incidente codificado por uma palavrachave que pudesse conferir sentido à unidade de análise. A análise foi conduzida pelo questionamento exaustivo do material empírico: "o que aconteceu? Onde aconteceu? O que é isso? O que representa?" que levou a um conjunto de códigos que, comparados e agrupados, receberam títulos que definiram três categorias temáticas: (1) Trilhas da corrupção (exemplo de códigos: nome dos países); (2) Redes - atores e envolvidos (exemplo de códigos: pessoas, autoridades e participantes); e (3) operações e esquemas (tipos de violações, crimes, ilegalidades). Essas categorias temáticas levam à questão central que configura a anatomia da corrupção transnacional.

\section{Dinâmicas da Corrupção Transnacionoal}

Nesta seção, apresentamos os resultados alcançados nesta pesquisa, iniciando com um resumo histórico do banco HSBC, abarcando desde a sua fundação até seu envolvimento nos escândalos financeiros dos últimos dez anos. Em seguida, apresentamos 5 casos de corrupção identificados no material empírico envolvendo o HSBC, e, ao final, discutimos as trilhas percorridas e as redes na corrupção transnacional identificadas por meio da análise de mapas e árvores de associação (Spink, 2010).

\section{1 "Our History": mercado do ópio e a glória}

"Our History" (Nossa História) é o título de um relatório publicado em 2013 pelo HSBC e divulgado no seu website, em 2015, sendo essa uma data próxima à comemoração dos 150 anos da instituição. Ao lado de um amplo registro fotográfico histórico, são narrados os marcos da trajetória de sucesso do banco (HSBC, 2013), mas sem revelar os contextos e eventos que associam a história do banco a guerras coloniais e comerciais conduzidas pelo Império Britânico na Ásia, os quais trazemos aqui de forma complementar (Le Monde, 2011).

No cenário comercial da época da criação do banco, (1811-1821), a Companhia Britânica das Índias Orientais mantinha intenso comércio com os chineses, comprando chá e vendendo o ópio trazido da Índia, comércio que chegou a representar metade das exportações britânicas nessa rota (Ming, 2018). A 
Anatomia da corrupção transnacional: Desvendando as teias e trilhas do dinheiro sujo em negócios legítimos

Primeira Guerra do Ópio que, em virtude da condição de debilidade dos soldados, terminou em 1842, com a derrota da China e a assinatura do primeiro "tratado desigual", o de Nanquim (Le Monde, 2011), obrigou o governo chinês a abrir cinco novos portos para o comércio internacional e a transferir a ilha de Hong Kong aos britânicos (Ming, 2018). A Segunda Guerra do Ópio (1856-1860) culminou em nova derrota da China e abriu às potências britânica e francesa a imposição de concessões territoriais sob administração estrangeira, a abertura de novos portos ao comércio estrangeiro e a legalização do comércio de ópio (Le Monde, 2011).

No cenário pós-guerra, o escocês Thomas Sutherland tornou-se superintendente e primeiro presidente da Hong Kong e Whampoa Dock (Companhia de Doca de Hong Kong e Whampoa), em 1863, quando nasceu o Hong Kong \& Shanghai Banking Corporation (HSBC) (Le Monde, 2011), sigla que, em chinês, traduz-se como "reunir", "colheita" e "riqueza" (Le Monde, 2011, p.3), ou como "abundância de remessas" ou "foco de riqueza" (HSBC, 2013, p. 3).

Ao final da primeira década de operação, o HSBC estava representado em sete países da Ásia, Europa e América do Norte e foi responsável por financiar a exportação de chá e seda da China, de algodão e juta da Índia, do açúcar das Filipinas, do arroz e da seda do Vietnã e pela importação da prata de São Francisco (HSBC, 2013). Entretanto, o banco reuniu suas primeiras riquezas graças ao ópio das Índias e, posteriormente, de uma província ao sudoeste da China, Yunnan (Le Monde, 2011). Com o recuo das atividades comerciais no decorrer da Primeira Guerra Mundial, o HSBC se aproximou dos anos 1920 com a intenção de se orientar para os mercados asiáticos, obtendo certo sucesso com essa estratégia. Entretanto, um dos piores momentos do banco viria durante a Segunda Guerra Mundial (1939-1945), quando se viu forçado a recuar e fechar unidades com o avanço do exército japonês e a transferir a sede de Hong Kong para Londres, entre 1941 e 1946. Após o final da guerra, com o fechamento das filiais na China continental, o banco voltou a concentrar suas atividades em Hong Kong (HSBC, 2013).

O pós-guerra abriu espaço para a expansão e diversificação do HSBC, com aquisições e fusões ao longo dos anos. Em 1959, o banco britânico-indiano Mercantile Bank, especializado em empresas locais de pequeno e médio porte, e com foco na Índia, foi adquirido e o The British Bank of the Middle East, antigo The Imperial Bank of Persia, também foi incorporado, com operações em todo o Golfo e, através do Oriente Médio, no norte da África. Em 1965, o HSBC assumiu participação majoritária no Hang Seng Bank, o principal banco privado chinês em Hong Kong e, com o início do programa chinês de reformas econômicas e modernização no final da década de 1970, o HSBC tornou-se o primeiro banco estrangeiro a obter uma licença bancária na China (HSBC, 2013).

O HSBC avançou para os Estados Unidos e Europa no período de 1980 a 1997 (Le Monde, 2011). Em 1992, fechou um acordo com o Midland Bank, do Reino Unido, assumindo a transferência da matriz da holding para Londres, atendendo aos requisitos das autoridades reguladoras (HSBC, 2013). Essa alteração ocorreu em 1993, antes da devolução do território à República Popular da China (Le Monde, 2011). Em 1999, o grupo realizou uma das últimas grandes aquisições/fusões, com o Republic New York Corporation, atualmente, integrado à HSBC USA Inc., assim como sua empresa irmã, o Safra Republic Holdings S.A. (Le Monde, 2011), hoje, HSBC Private Bank, em Luxemburgo. Em 2007, alcançou a posição de 8o maior banco do mundo em 2010 (Forbes, 2010).

Nos EUA, em fevereiro de 2010, o Subcomitê Permanente de Investigações do Senado publicaria um relatório de investigações denominado "Keeping Foreign Corruption out of the United States: Four Case Histories", que procurava analisar como autoridades estrangeiras politicamente poderosas e seus agentes próximos, denominados em acordos internacionais como PEPs, utilizavam o serviço de instituições financeiras dos EUA para movimentar fortunas, manipulando salvaguardas contra lavagem de dinheiro e anticorrupção. Os casos referem-se a eventos entre 2000 a 2008, envolvendo a Guine Equatorial, Gabão, Nigéria e de Angola, neste último, com investigações diretas sobre a partição do HSBC em relação à não observância de instruções legais dos EUA (PERMANENT SUBCOMMITTEE ON INVESTIGATIONS OF UNITED STATES SENATE, 2010).

Em maio do mesmo ano, o Her Majesty's Revenue and Customs (HMRC) teria recebido do governo francês a versão britânica reconstruída dos dados de contas bancárias do HSBC Private Bank Swiss obtidas do delator Hervé Falciani, então conhecida como swiss disc (disco suíço). O material revelava nomes e 
os detalhes de transações bancárias de 6.000 britânicos, considerados potenciais evasores de impostos, referente a um período em que Lord Green presidia a instituição (LEIGH, et al., 2015g).

Por fim, em outubro de 2010, o Office of the Comptroller of the Currency (OCC), órgão controlador dos EUA, anunciaria uma Cease and Desist Order (Ordem de Cessar e Desistir) contra o HSBC por violar o Bank Secrecy Act (BSA - Lei do Segredo Bancário), no período de 2006 a 2009, exigindo que a organização adequasse seu sistema de conformidade legal em decorrência de deficiências relacionados aos relatórios de atividades suspeitas, monitoramento de compras e transferências financeiras internacionais, due diligence de clientes de afiliadas estrangeiras e avaliação de risco com relação aos PEPs (OFFICE OF THE COMPTROLLER OF THE CURRENCY, 2010).
Apesar da autuação, o OCC seria duramente criticado, em 2012, pelo Subcomitê Permanente de Investigações do Senado norte-americano por tolerar deficiências contra lavagem de dinheiro e por ineficiência das sanções, permitindo que bancos norte-americanos postergassem a correção de seus problemas internos (DENNIS, 2012). As repreensões vieram em meio à publicação de outro relatório pelo Subcomitê, em julho de 2012, dessa vez, com o título "U.S. Vulnerabilities to Money Laundering, Drugs, and Terrorist Financing: HSBC Case History" (Vulnerabilidades nos EUA para Lavagem de Dinheiro, Drogas e Financiamento ao Terrorismo: Histórico do Caso HSBC) (PERMANENT SUBCOMMITTEE ON INVESTIGATIONS OF UNITED STATES SENATE, 2012).

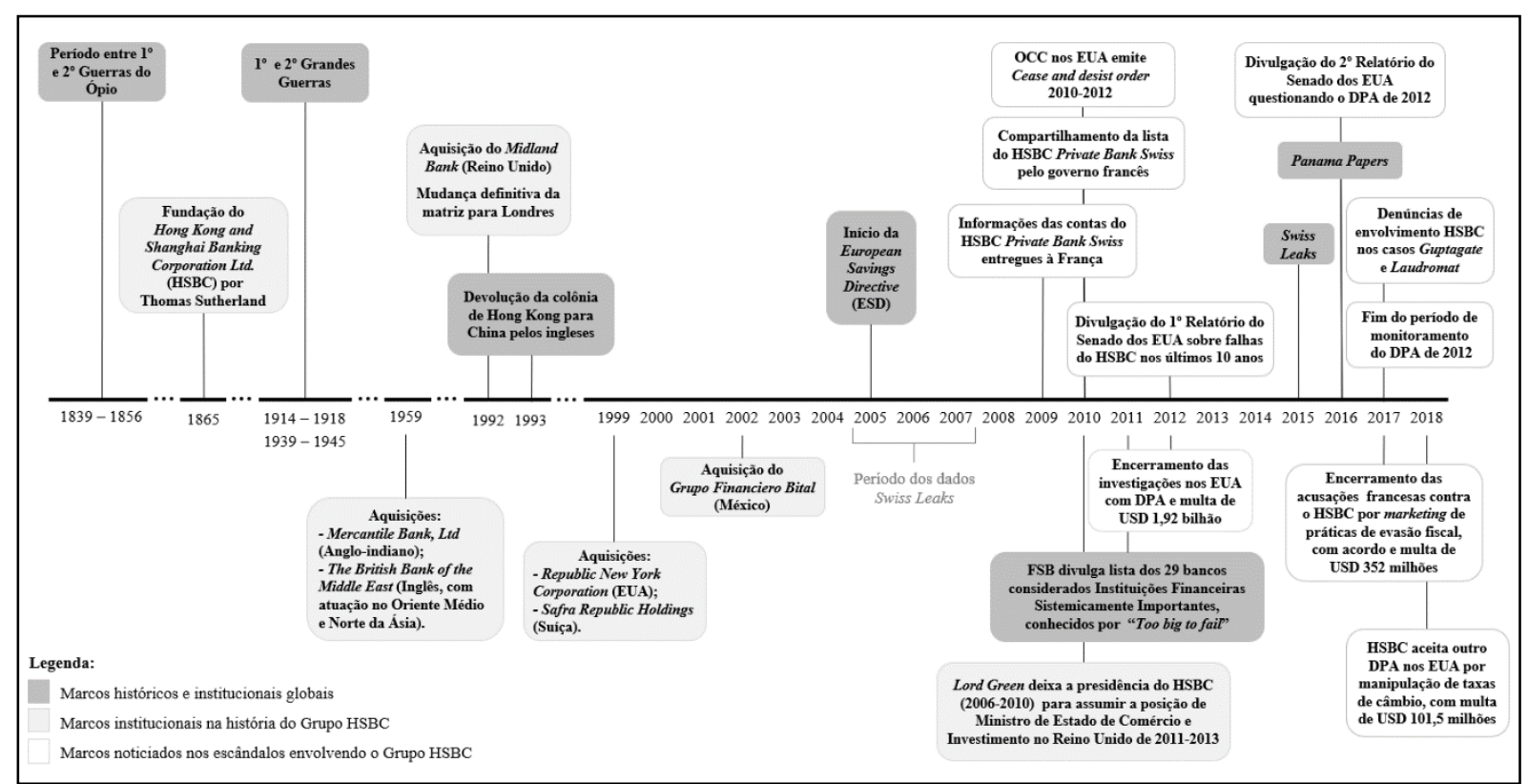

Figura 1: Cronologia dos marcos históricos do HSBC

Fonte: elaborada pelas autoras com base nos dados da pesquisa

Nesta seção, nós complementamos o documento "Our History" com informações dos principais escândalos envolvendo o HSBC e a corrupção transnacional citados nas reportagens que compõem o corpus de análise desta pesquisa. Essas informações complementares na cronologia dos marcos históricos do HSBC (Figura 1) ilustram o contexto histórico da participação de negócios ilícitos nas operações do banco e justificam a nossa escolha do HSBC como ponto de análise da dinâmica da corrupção transnacional, visto que ele se encontra entre os mais citados quando se fala de dinheiro sujo (GLOBAL
WITNESS, 2015), além de o histórico da instituição revelar sua proximidade com o fenômeno de longa data.

\subsection{HSBCGate: 5 casos envolvendo o HSBC}

A análise dos documentos resultou na identificação de cinco casos de corrupção envolvendo o HSBC, os quais são descritos de forma resumida nesta seção e, posteriormente, analisados 
em seu conjunto para alcançar o objetivo proposto na pesquisa.

\subsubsection{Too big to fail, too big to jail}

Em 11 de dezembro de 2012, o HSBC admitiu ter violado o Bank Secrecy Act (BSA), o International Emergency Economic Powers Act (IEEPA) e o Trading with the Enemy Act (TWEA). A violação ao BSA decorreu da não manutenção de um programa eficaz de combate à lavagem de dinheiro e da não realização das devidas diligências aos seus correntistas estrangeiros correspondentes, permitindo que, entre 2006 e 2010, traficantes de drogas mexicanos lavassem dinheiro através dos EUA. Já as violação ao IEEPA e ao TWEA decorreram da realização de transações ilegais, entre meados da década de 1990 e 2006, em nome de clientes em Cuba, Irã, Líbia, Sudão e Mianmar, que eram países sujeitos a sanções impostas pelo Office of Foreign Assets Control (OFAC) no momento das transações (DOJ, 2012).

Alguns meses depois, uma equipe do U.S. House of Representatives Financial Committee dos EUA iniciaria uma avaliação sobre a decisão do Departamento de Justiça (DOJ) estadunidense de não processar o HSBC ou qualquer um de seus executivos ou funcionários, divulgando o resultado desse trabalho, em 2016, em um relatório intitulado: "Too Big to Jail: Inside the Obama Justice Departament's Decision not to hold Wall Street Accountable" (Dash, 2011), elaborado a partir de documentos do processo obtidos após grande insistência junto ao Tesouro estadunidense, bem como de entrevistas com alguns funcionários da época. A conclusão do relatório aponta que os documentos do Tesouro fornecem evidências de que a liderança do DOJ se recusou a seguir a recomendação da sua equipe jurídica para processar o HSBC porque estavam preocupados com o potencial desastre financeiro global sugerido, repetidas vezes, pelo Financial Services Authority FSA (Hardouin, 2017). Logo, há evidências de que o envolvimento do Reino Unido desempenhou um papel crucial na decisão de não se processar o banco (U.S. House Of Representative, 2016).

\subsubsection{Swiss Leaks}

O modelo operacional do HSBC Holding é estruturado em um centro corporativo e quatro empresas globais segmentadas em: banco de varejo e finanças (Retail Banking and Wealth Management); banco comercial (Commercial Banking); banco corporativo e institucional (Global Banking and Markets); e banco privado, especializado em High Net Worth Individuals - HNWI (Global Private Banking) (HSBC, 2018). Esses quatro negócios, com algumas variações quanto à estratégia, existem desde 2006 (HSBC, 2007), ano em que o engenheiro de tecnologia da informação, o franco-italiano Hervé Falciani, foi transferido do HSBC de Mônaco para o HSBC Private Bank, em Genebra, com o intuito de melhorar os sistemas de supervisão e proteção a dados dos clientes, mas disse ter encontrado resistência, conforme sua versão da história para as autoridades francesas (Hamilton, 2015).

A questão da evasão fiscal que viria a público tem um contexto anterior, qual seja, da entrada em vigor, em julho de 2005, da European Savings tax Directive (ESD - Diretiva Europeia sobre Tributação da Poupança). A lei exigia que membros da União Europeia (EU) e outros países divulgassem os nomes dos detentores de contas residentes na UE e os lucros obtidos para seus países de origem. Países com leis de sigilo bancário, como a Suíça, foram autorizados a omitir essas informações em troca da cobrança de $15 \%$ de imposto retido na fonte e remetido para a nação de residência do cliente. Inicialmente, o programa funcionou bem e os impostos compartilhados pela Suíça quase triplicaram no primeiro ano. Entretanto, a lei se referia apenas a pessoas, e não a corporações, e foi justamente essa lacuna que o HSBC Private Bank utilizou para estruturar operações que permitiam transformar pessoas em corporações para finalidades fiscais (Chittum, 2015; Smith, \& Babcock, 2015).

\subsubsection{Panamá Papers}

Um conjunto de documentos referente à criação e movimentação de contas offshore, desde o início da década de 1970, pelo escritório de advocacia panamenho Mossack \& Fonseca, contendo cerca de 214000 empresas, identidade dos acionistas e administradores, foi enviado, em 2015, por uma fonte anônima, para o jornal alemão Süddeutsche Zeitung, e, posteriormente, para o ICIJ. Analisadas por cerca de 400 jornalistas, em mais de 80 países, as revelações seriam divulgadas no início de 2016 em uma série de reportagens intitulada "Panama Papers" (ICIJ, 2016). 
Em fevereiro de 2017, a polícia do Panamá prendeu os fundadores da Mossack \& Fonseca, Ramon Fonseca e Jurgen Mossack, acusados de lavagem de dinheiro, como parte das investigações sobre o maior escândalo de suborno do Brasil, a operação "Lava Jato". Em março de 2018, o escritório anunciou que encerraria o restante das suas operações, declarando em comunicado enviado aos clientes e divulgado pelo ICIJ que: "A deterioração da reputação, a campanha de mídia, o cerco financeiro e as ações irregulares de algumas autoridades panamenhas causaram danos irreparáveis, cuja consequência obrigatória é a cessação total das operações para o público" (Fitzgibbon, 2018, p.1).

Governos de todo o mundo já teriam recuperado, aproximadamente, USD 700 milhões em multas e impostos atrasados como resultado da investigação do Panama Papers e a quantidade, provavelmente, continuará a crescer à medida que as investigações sobre os dados continuarem e novas revelações forem feitas. Os últimos documentos mostraram as reações ao vazamento de banqueiros, contadores e advogados que, em conjunto com o escritório panamenho, auxiliavam celebridades e milionários a evitar ou reduzir impostos por meio de empresas offshore (Gallego, 2018).

\subsubsection{Forex (Foreign Exchange)}

Em dois casos, os operadores da mesa de câmbio utilizaram informações confidenciais, fornecidas a eles por clientes, para que grandes transações fossem executadas de maneira a direcionar o preço da libra esterlina de modo que beneficiasse o HSBC e suas próprias contas pessoais em detrimento de seus clientes. O DOJ chegou aos termos do Deferred Prosecution Agreements (DPA) em função das medidas corretivas do banco até aquele momento, incluindo a dedicação de recursos significativos para melhorar seus sistemas e controles e a demissão dos funcionários envolvidos em irregularidades. Tanto o ex-diretor de operações cambiais quanto o chefe de câmbio do HSBC também foram processados (DOJ, 2017). Esse não foi o primeiro e único envolvimento do banco em manipulação de taxas de câmbio contido nas reportagens selecionadas pela pesquisa.

Em 2014, reguladores dos EUA e do Reino Unido impuseram multas de $£ 2,6$ bilhões a seis grandes bancos por fraudaram um mercado de câmbio com dimensões de 4,5 trilhões de libras/dia. No Reino
Unido, foram autuados UBS (£ 233 milhões), Citibank (£ 225 milhões), JPMorgan ( $€ 222$ milhões), RBS ( $€$ 217 milhões) e HSBC (£ 216 milhões). Nos EUA, foram multados o Citibank e o JP Morgan (USD 310 milhões cada), o Royal Bank of Scotland (RBS) e Union Bank of Switzerland (UBS) (USD 290 milhões cada) e HSBC (USD 275 milhões), remetendo as acusações ao período entre 2008 e 2013. Segundo as investigações, os operadores desses bancos se reuniam em salas de chat e trocavam informações confidenciais de clientes com o intuito deliberado de manipular as taxas de câmbio a favor das instituições, conforme transcrições de várias dessas conversas (Treanor, 2014).

\subsubsection{Global Laundromat}

O nome "Global Laundromat" (lavanderia global) foi dado pelo Organized Crime and Corruption Reporting Project (OCCR) a um projeto feito a partir de dados obtidos de fontes que desejam permanecer anônimas, tendo sido compartilhado com parceiros de mídia de 32 países. Divulgado no início de 2017, trata-se de um vasto esquema bilionário de lavagem de dinheiro, ocorrido entre 2010 e 2014, da Rússia para a Europa, EUA e outros países. O esquema funcionava por meio de empresas fictícias que participavam de um engenhoso esquema de simulação de empréstimos falsos e avalistas, utilizando bancos na Moldávia e na Letônia. Muitas dessas simulações eram registradas em Companies House em Londres, onde os verdadeiros donos permanecem secretos devido ao anonimato proporcionado pela polêmica legislação offshore.

As autoridades já localizaram cerca de USD 20 bilhões em dinheiro sujo envolvendo uma rede de 96 países, mas estimam que o total possa chegar a USD 80 bilhões, envolvendo cerca de 500 pessoas, incluindo oligarcas, banqueiros de Moscou e figuras próximas ou ligadas ao Federal Security Service (Serviço de Segurança Federal) russo, sucessor da agência de espionagem KGB (Harding, Hopkins, \& Barr, 2017). Na continuidade das investigações do OCCR, seria divulgada, em setembro de 2017, uma nova fase do projeto denominada "lavanderia do Azerbaijão", referente ao envio de USD 2,9 bilhões da capital do Azerbaijão, por meio de um banco dinamarquês, para contas em quatro empresas anônimas registradas em Londres. Supostamente, o dinheiro foi utilizado para pagamentos a políticos europeus, na Itália e na Alemanha, para desviar 
críticas relativas ao histórico de direitos humanos do Azerbaijão, fazendo com que vários deles votassem contra moções censurando o país na Assembleia Parlamentar do Conselho da Europa (Harding, 2017).

\subsubsection{Guptagate}

O escândalo "Guptagate" teve início em 2013 quando, decorrente da proximidade entre as famílias do então presidente da África do Sul, Jacob Zuma e dos Guptas, os últimos foram autorizados a utilizar a base aérea sul-africana para fins pessoais, como um presente particular do presidente. Seguiu-se, em 2016, a divulgação de um relatório do ex-protetor público da África do Sul, Thuli Madonsela, contendo acusações de que os Guptas haviam oferecido a alguns políticos cargos de ministros e valores consideráveis em dinheiro, bem como acusações de que a empresa britânica de relações públicas, Bell Pottinger, contratada por uma das empresas de Gupta, havia tentado incitar a ira racial na África do Sul em um momento delicado da crise política que se instalara com as denúncias de corrupção (CAVE, 2017).

O envolvimento do HSBC surgiu em outubro de 2017 quando Lord Hains, parlamentar britânico e exativista antiapartheid, entregou às autoridades britânicas, solicitando que fossem investigadas com prioridade, supostas provas do envolvimento de bancos britânicos - HSBC e Standard Chartered - nos esquemas de corrupção que haviam se instaurado naquele país, alertando sobre "uma possível cumplicidade criminosa" (DAVIES, 2017a, p.1). Em novembro de 2017, o HSBC emitiu um comunicado revelando que havia fechado as contas vinculadas à investigação de corrupção da família Gupta, admitindo, pela primeira vez, preocupações sobre suas possíveis ligações com o escândalo. Na ocasião, o banco emitiu uma declaração em resposta às evidências contidas no Gupta Leaks (Vazamentos Gupta), uma série de e-mails vazados investigados em reportagens divulgadas na África do Sul que revelam, entre outros casos, contas bancárias do HSBC em Dubai. Essas contas, supostamente, eram utilizadas para canalizar milhões de dólares de empresas associadas aos contratos de venda de locomotivas ferroviárias chinesas para a África do Sul, sendo os contratos fechados em dólares e autorizados pelo escritório do banco em Nova York (DAVIES, 2017b).

\subsection{Teias e Trilhas da Corrupção Transnacional}

Para examinar a corrupção transnacional, organizamos o material empírico com base em três questões: (1) qual a abrangência dos esquemas de corrupção? (2) quais atores envolvidos na dinâmica de corrupção transnacional? e (3) quais padrões dos esquemas operados? Essa análise resultou em nove temas intermediários resultantes da associação de categorias (denominados códigos no software ATLAS.ti 8), que são o nível primário da análise realizada, representando um conjunto de informações com características comuns, sendo esses: 1. Clientes com reputação duvidosa; 2. Redes financeiras para atender contraventores; 3 . Corrupção política; 4. Fragilidades institucionais; 5. Interesses políticos; 6. Acusações e denúncias; 7. Autoridades envolvidas; 8 . Fronteiras ultrapassadas; 9. Tipos de crimes e ilegalidades.

Assim, cada um desses temas revela um aspecto do corpus e decorre de um trabalho iterativo de leitura, análise e associação, tendo resultado em três categorias: (1) Trilhas da corrupção; (2) Redes atores e envolvidos; e (3) operações e esquemas, as quais configuram a anatomia da corrupção transnacional (Figura 2). 


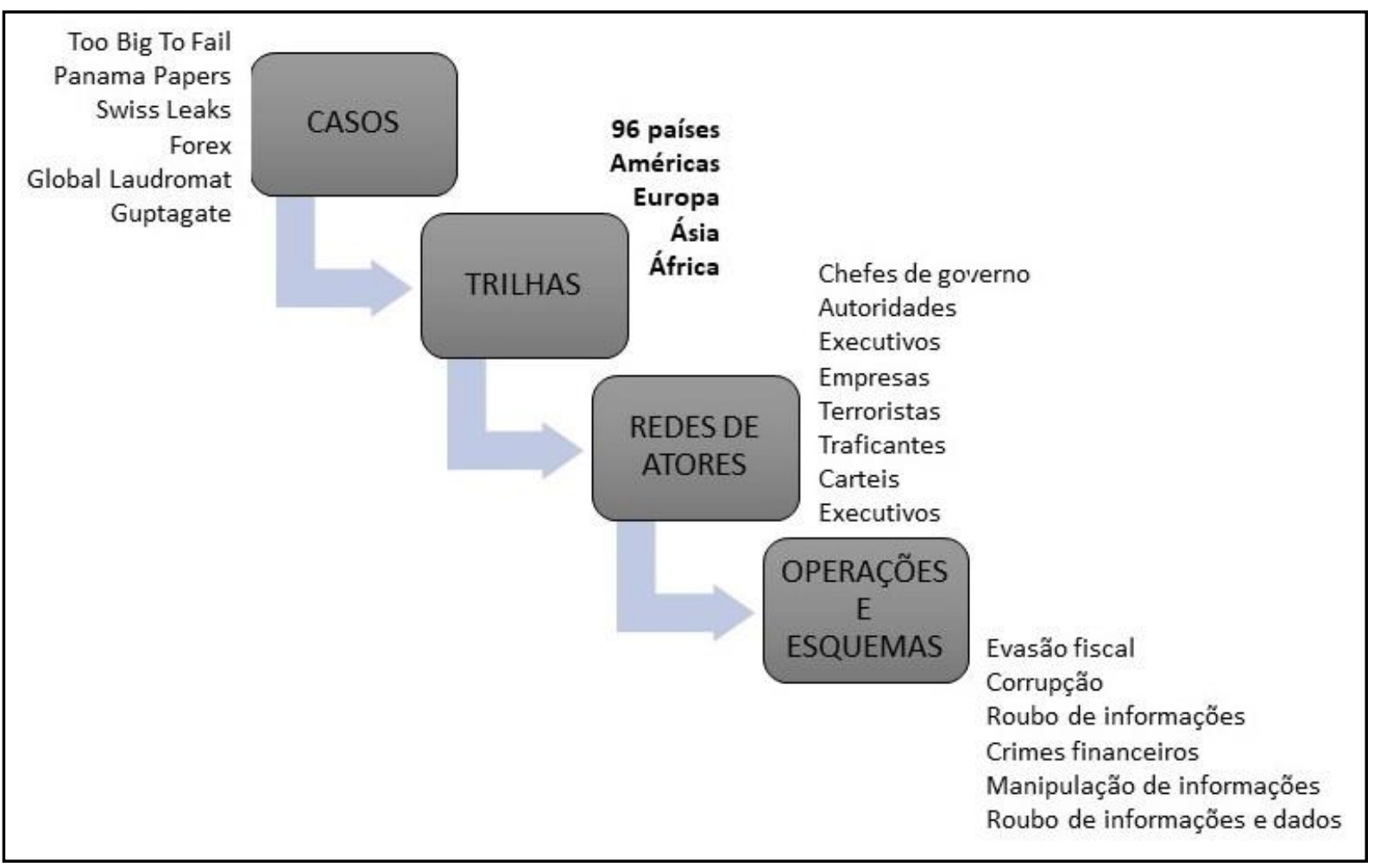

Figura 2: Anatomia da Corrupção Transnacional: caso HSBC

Fonte: elaborada pelas autoras com base nos dados de pesquisa

A análise desta pesquisa encontrou indícios que levam aos mesmos caminhos de controles frouxos e lenientes que propiciaram a cumplicidade com contraventores observada nos casos denominados nesta pesquisa como "Too big to fail", "Swiss Leaks", "Forex" e "Global Laundromat", dando um novo sentido ao seu objetivo institucional de "[...] estar onde está o crescimento, possibilitando que os negócios e economias prosperem e, por fim, ajudando pessoas a realizarem suas esperanças e concretizarem suas ambições" (HSBC, 2018, p. ii). Os casos são caracterizados pela corrupção transnacional, cuja definição compreende o envolvimento de uma organização ou grupo criminoso (HSBC); existência de, pelo menos, um elemento transnacional (atuação em 96 países); e o ato corrupto (as operações descritas nos 5 casos) que acontece nessas circunstâncias (Basteskas, 2006)

As trilhas da corrupção dos casos analisados apontam que a corrupção percorreu os continentes Americano (USA, Brasil, México, Cuba, Argentina, Colômbia), Europeu (Mônaco, Reino Unido, Suíça, Islândia, Itália, Alemanha, França, Moldávia, Letônia), Ásiático (China, Hong-Kong, Coreia do Norte, Índia, Mianmar, Síria, Ucrânia, Rússia, Malásia, Paquistão, Emirados Árabes Unidos, Irã, Azerbaijão) e Africano (África do Sul, Sudão, Líbia, Arábia Saudita, Angola,
Gabão, Guiné Equatorial). Além desses países, o material analisado cita ainda que os esquemas de corrupção abrangeram 96 países, muitos deles sancionados ou sujeitos a sanções impostas pelo Office of Foreign Assets Control.

A figura 1 traz os marcos históricos globais e institucionais no HSBC, desde a origem do banco, no período da expansão mercantilista inglesa e do lucrativo comércio de ópio na China (Le Monde, 2011), até os escândalos com envolvimento do banco, a partir de investigações das autoridades estadunidenses, divulgadas em 2010 e 2012. Durante sua trajetória (Figura 1), o banco apresentou um comportamento ora leniente, ora proativo, com ditadores africanos, traficantes de drogas latinoamericanos, terroristas árabes e tantos outros suspeitos ou bloqueados por sanções internacionais por mais de uma década (Rushe \& Treanor, 2012).

A análise identificou duas redes: os atores (participantes do lado da oferta) e dos envolvidos (lado da demanda). Para operacionalizar os esquemas de corrupção, O HSBC contou com a participação de diversos atores, como o chefe de conformidade do HSBC, o executivo-chefe de banco de varejo e gestão de patrimônio, funcionários de médio escalão do banco, engenheiro de tecnologia da informação, ex-diretor de operações cambiais, chefe 
Anatomia da corrupção transnacional: Desvendando as teias e trilhas do dinheiro sujo em negócios legítimos

de câmbio do HSBC, subsidiária suíça, empresas offshore, Lord Green (ex-presidente do banco que assumiu o cargo de Ministro de Estado e Comércio e Investimento no Reino Unido), autoridades tributárias inglesas, o grupo Mossack \& Fonseca, a KPMG, McKinsey, SAP e operadores de seis grandes bancos internacionais.

Quanto aos envolvidos, foram citados: procurador-geral adjunto, traficantes de drogas mexicanos, financiadores de terroristas, traficantes de armas, empresas de fachadas, Cartel de Sinaloa (México), Cartel Norte Del Valle (Colômbia), narcotraficantes, presidente do Federal Reserve (Bem Bernanke), chanceler do tesouro do Reino Unido (George Osborne), chefes de estado em exercício de cinco países, políticos, familiares e colaboradores próximos de vários chefes de governo de mais de 40 países, 29 multimilionários litados pela Forbes, dezenas de empresas e pessoas sancionadas nas listas negras da OFAC dos USA, 500 pessoas incluindo oligarcas, banqueiros de Moscou e figuras públicas, família do presidente sul-africano Jacob Zuma e da família Gupta do escândalo Guptagate, a empresa britânica de relações públicas (Bell Pottinger), sonegadores fiscais e outros transgressores da lei.

A atuação dos intermediários nos esquemas de corrupção, particularmente do HSBC, não pode ser considerada apenas passiva, uma vez que as investigações concluídas deixam claro que o banco conhecia os esquemas e colaborava com os negócios de seus clientes, o que aponta para uma cumplicidade. Apesar das alegações e condenações referenciando a fragilidade do sistema de monitoramento e controle, as evidências apuradas pelas autoridades demonstram conivência, como, por exemplo, nas adaptações bancárias para os depósitos dos cartéis de droga no México, na manipulação de dados de transferências para atender clientes sancionados (Permanent Subcommittee On Investigations Of United States Senate, 2012), nas revelações das notas e dos clientes da afiliada suíça (Ryle, 2015) e na quantidade de empresas de fachada solicitadas por meio do escritório Mossack \& Fonseca (ICIJ, 2017).

Nessa rede de atores, distinguem-se o lado da demanda (os corrompidos) e o lado da oferta (os corruptores) (Heimann \& Boswell, 1998) que operacionalizam esquemas de corrupção além das fronteiras, envolvendo uma rede de atores com o intuito de obterem grandes lucros (Sung, 2005; Bahoo, Alon, \& Palmitrieri, 2020).

As operações ou esquemas citados são: suborno, lavagem de dinheiro, violação de segredo bancário, transações ilegais, crime financeiro, cópia ilegal de informações confidenciais de clientes, roubo de dados de clientes, manipulação de taxas de câmbio, esquema de fraude conhecido como "front-running" (direcionar o preço da libra esterlina em benefício do banco), venda de dados de clientes, evasão fiscal, transformação de pessoas físicas em pessoas jurídicas para finalidades fiscais, sonegação fiscal, pagamento de políticos europeus, incentivo a cidadãos ricos para esconderem ativos das autoridades fiscais, fraudes, troca de informações de clientes. Essas operações contaram com a negligência e cumplicidade do HSBC, pois constataram-se leniência, a não realização das devidas diligências aos seus correntistas estrangeiros correspondentes, falhas na supervisão, falta de controle dos sistemas de conformidade

Em conjunto, esses escândalos ilustram a dinâmica da corrupção transnacional por meio da participação do banco HSBC conectado a outros atores considerados legítimos, como o escritório de advocacia Mossack \& Fonseca, que estabelecia empresas de fachada em paraísos fiscais, ou as Companies House britânicas, agências do governo que permitem a abertura de empresas sem identificação dos reais beneficiários. Essas redes transnacionais, compostas por vários intermediários legais, estabelecem arranjos complexos para manter uma fachada de conformidade para as transações financeiras (Christensen, 2011; Cooley; Sharman, 2015; Platt, 2017), ocultando não só os pagamentos e lavagem de dinheiro corrupto, mas beneficiando também o tráfico de armas, de drogas, de diamante e o terrorismo.

O que se observa nessa dinâmica é que os benefícios da corrupção estão de um lado, e as consequências, de outro, visto que a instituição bancária que lucra com as transações financeiras é britânica e os principais paraísos ficais utilizado para ocultar os pagamentos também estão no Hemisfério Norte, como os territórios britânicos, Suíça, EUA e Hong Kong. Do outro lado, estão as vítimas, sejam elas dos cartéis de drogas Latino-americanos, de governos corruptos ou traficantes no Oriente Médio, África e Leste Europeu. As operações identificadas na pesquisa se aproximam dos achados de Ware e 
Noone (2005): pagamento de propinas, utilização de operadores (brokers), empresas de fachada, estabelecimento de cartéis para fraudar licitações públicas, utilização de empresas de familiares do governo e, diretamente, fraude de contas do governo e abuso de bens públicos

Na mesma direção que Lasslet (2017), este estudo mostrou as características elementares de um esquema de corrupção que ultrapassa as fronteiras transnacionais: os atores, as redes, os esquemas e as trilhas percorridas para operacionalizar formas complexas de manipulação regulatória e de mercado. Adicionalmente, esta pesquisa revelou a interseção entre o crime internacional e os negócios legítimos, ampliando o conhecimento sobre o comportamento potencialmente ilegal e antiético de um dos maiores bancos do mundo. Os documentos revelam como o HSBC se beneficiava de clientes, tais como traficantes de armas, ditadores e contrabandistas de diamantes de sangue, bem como explicitavam seu envolvimento ilegal na estruturação de operações de elisão fiscal voltada para clientes europeus (Ryle, et al., 2015b).

O vazamento de documentos confidenciais do escritório de advocacia panamenho Mossack \& Fonseca, caso conhecido por Panama Papers, revelou um panorama inédito do mundo dos paraísos fiscais, proporcionando uma visão detalhada, entre 1977 e 2015, de como o dinheiro não contabilizado flui pelo sistema financeiro global (ICIJ, 2016). A análise dos documentos vinculou empreiteiras brasileiras envolvidas na Lava Jato a algumas empresas offshore operadas pelo escritório, além de identificar integrantes, ou parentes desses, de sete partidos brasileiros (BBC MUNDO, 2016). O HSBC não era o único grande banco envolvido no vazamento, mas o conjunto das suas subsidiárias contava com o maior número de solicitações de contas offshore na lista do escritório panamenho (ICIJ, 2016).

Assim como apontado na revisão da literatura, os ganhos financeiros, na forma de compensação ou bônus, podem ser um incentivo para violar a lei (Tenbrunsel, \& Thomas, 2015, p.3), o que pode sinalizar para um problema de agência (Bahoo, Alon \& Paltrinieri, 2020).

\section{Considerações Finais}

Nesta pesquisa, nós ilustramos a anatomia da corrupção transnacional a partir de um caso específico, apontando as trilhas em que a corrupção percorre entre vários paises e a rede formada para operar diversos esquemas e operações envolvendo um fenômeno transnacional. O material empírico analisado permitiu apresentar a linha do tempo do banco, com seus marcos históricos e institucionais que envolvem o banco e a corrupção transnacional. As especulações apontam para um comportamento do banco ora leniente, ora proativo, com ditadores africanos, traficantes de drogas latino-americanos, terroristas árabes e tantos outros suspeitos ou bloqueados por sanções internacionais por mais de uma década (Rushe \& Treanor, 2012), desde a sua origem, no período da expansão mercantilista inglesa e do lucrativo comércio de ópio na China (Le Monde, 2011). Tais comportamentos também são apontados nas investigações de 2010 a 2012 feitas pelas autoridades estadunidenses.

Esta pesquisa traz contribuições teóricas, metodológicas e práticas. Ao abordar o tema corrupção transnacional, a partir de um contexto e um setor específico, a pesquisa permitiu examinar o fenômeno de modo a ilustrar o alcance e as relações entre atores e envolvidos nos escândalos, que se estenderam além dos continentes e por vários anos. Nós examinamos uma grande quantidade de informações, as quais foram colocadas em um contexto para analisar a corrupção como um fenômeno transnacional, o que permite avaliar impactos sociais, internacionais, econômicos e politicos.

A contribuição teórica proposta pela pesquisa está na compreensão dos esquemas de corrupção e suas respectivas articulações, o que permite a conformação das redes transnacionais entre instituições financeiras e contraventores, contribuindo para a perenidade da corrupção. A abordagem utilizada nesta pesquisa contribui ao fornecer uma análise sobre um caso particular, lançando luzes sobre como a corrupção transnacional é operacionalizada, fornecendo uma base adequada para análise de outros casos, tendo como ponto de partida uma companhia transnacional. Ademais, nossa pesquisa inclui as origens históricas da corrupção na organização analisada, o que é um elemento importante na análise da corrupção. Nós mostramos que a corrupção transnacional envolve uma rede de atores que protagonizam negócios lícitos e ilícitos, portanto, a análise dessas relações complicadas permite compreender melhor as causas da corrupção transnacional, as quais não se limitam 
ao setor público e nem mesmo a negócios e governos locais.

Partindo-se do argumento de Lambsdorff e Schulze (2015), para quem a corrupção sistêmica afeta todo o sistema político-econômico, a compreensão das estruturas de incentivo projetadas para manter o sistema corrompido constitui-se no primeiro passo para projetar políticas anticorrupção realmente efetivas. A relevância desse argumento se encontra no fato de que escândalos de corrupção não são fenômenos recentes e, dentre as importantes crises políticas mundiais, muitas tiveram como origem escândalos políticos midiáticos, destacandose, dentre os mais célebres, o caso Watergate, na década de 1970, que levou à renúncia do presidente Richard Nikon nos EUA e, no Brasil, aquele que levou Getúlio Vargas ao suicídio, em 1954, e à renúncia do presidente Fernando Collor, em 1992.

A corrupção tem um efeito devastador para a legitimidade dos regimes democráticos e, consequentemente, para a promessa de igualdade política. Por um lado, ela induz parcelas importantes da opinião pública a considerarem que a lei não é efetiva, posto que nem todo ilícito é igualmente punido e, por outro, também desequilibra os modos pelos quais políticas públicas são definidas, já que, em alguns projetos, apropriações privadas de fundos públicos são recorrentes.

O estudo sobre corrupção transnacional é uma tarefa desafiadora no sentido de conduzir estudos consistentes, visto ser necessário superar barreiras culturais, principalmente, em relação ao idioma, para obter e analisar as informações, pois esses tipos de casos envolvem diversos países de diferentes idiomas. Ademais, o acesso a dados para esse tipo de pesquisa consiste em um obstáculo, pois é improvável que esquemas e operações entre funcionários corruptos sejam passíveis de exibição pública, a menos que os casos sejam expostos na imprensa ou estejam sob investigação. Nesse sentido, este estudo alcançou o objetivo considerando uma fonte de informações vigorosa, relevante e confiável.

As contribuições práticas são dirigidas a gestores de companhias com alcance local e internacional, no sentido de que esses tenham entendimento das consequências desse fenômeno e, ainda, como negócios legítimos podem entrar nas trilhas do dinheiro criminoso quando do envolvimento em operações e ligações perigosas, o que exige cautela por parte dos tomadores de decisões. Acreditamos que a compreensão das estruturas envolvidas na corrupção transnacional possa ampliar ou, até mesmo, estabelecer um pensamento crítico quanto à atuação dos gestores nos contextos de dominação em que estão inseridos, seja global ou localmente. Isso pode contribuir para reflexões sobre sua capacidade de planejar e conceber políticas e estruturas de governanças mais adequadas e coerentes com o sentido verdadeiramente esperado para uma atuação socialmente responsável.

Por fim, entendemos que a pesquisa tem limitações, as quais podem ser superadas com futuros estudos, como, por exemplo, analisar com maior profundidade um caso específico e explorar fatores políticos e culturais que podem afetar a corrupção trasnacional, considerando os países que se beneficiaram e aqueles que foram impactados de forma prejudicial. No caso desta pesquisa, ao considerar cinco casos com envolvimento de um único banco, nós ganhamos na abrangência, mostrando que as práticas são recorrentes e não acidentais, e perdemos na profundidade da apresentação dos resultados. Outra sugestão que não foi abordada nesta pesquisa, porém, a revisão da literatura aponta como uma lacuna no campo da administração, é a análise da corrupção transnacional como um crime contra a humanidade, o que pode ser pesquisado percorrendo caminhos que busquem explorar o envolvimento dos gestores corporativos e suas interpretações sobre o fenômeno.

\section{REFERÊNCIAS}

Avritzer, L. et al. (2012.). Corrupção: ensaios e críticas. Editora/UFMG.

Babcock, C. Prying Eyes? Sovereign Has You Covered. (08/02/2015). ICIJ. Disponível em: $<$ https://www.icij.org/investigations/swissleaks/prying-eyes-sovereign-has-you-covered/>.

Bahooa, S., Alonb, I., \& Paltrinieria, A. (2020). Corruption in international business: A review and research agenda. International Business Review, 29, $1-24$.

Bantekas, I. (2006). Corruption as an International Crime and Crime against Humanity: An Outline of Supplementary Criminal Justice Policies. Journal of International Criminal Justice, 4(3), 466-484. 
BBC Mundo. (2016) Panama Papers: como escândalo chega ao Brasil e à América Latina. BBC BRASIL. (5/4/2016). Disponível em:< http://www.bbc.com/portuguese/noticias/2016/04/ 160405_panama_papers_america_latina_lab>.

Cave, A. (2017) Deal that undid Bell Pottinger: inside story of the South Africa scandal. (5/9/2017). The Guardian. Disponivel em: <https://www.theguardian.com/media/2017/sep/05 /bell-pottingersouth-africa-pr-firm>.

Chittum, R. (2015). Diamond Dealers In Deep Trouble As Bank Documents Shine Light On Secret Ways. (08/02/2015). ICIJ. Disponível em: <https://www.icij.org/investigations/swissleaks/diamond-dealers-deep-trouble-bankdocuments-shine-light-secret-ways/>.

Cooley, A., \& Sharman, J.C.(2015) Blurring the line between licit and illicit: transnational corruption networks in Central Asia and beyond. Central Asian Survey, 34(1),11-28.

Cooley, A., \& Sharman, J.C.(2017) Transnational Corruption and the Globalized Individual. Perspectives on Politics, 15(3),732-753.

Christensen, J. (2011) The looting continues: tax havens and corruption. Critical Perspectives on International Business, 7(2), 177-196.

Dash, E. (2011). If It's Too Big to Fail, Is It Too Big to Exist? (20/06/2009). The New York Times. Disponível em: <https://www.nytimes.com/2009/06/21/weekinrevi ew/21dash.html?partner=rss\&emc $=$ rss $>$.

Davies, R. (2017a) HSBC 'complicit' in South Africa scandal, House of Lords told. (01/11/2017). The Guardian. Disponível em: <https://www.theguardian.com/business/2017/nov/ 01/hsbc-investigated-fund-transfers-south-africacorruption-row-zuma-gupta>.

Davies, R. (2017b) HSBC shut down accounts linked to Gupta scandal. (10/11/2017). The Guardian. Disponível em: <https://www.theguardian.com/business/2017/nov/ 10/hsbc-shut-down-accounts-linked-to-guptascandal>.
Dennis, B. (2012). Senate report criticizes HSBC for inadequate internal controls. (16/07/2012). The Washington Post. Disponível em: < https://www.washingtonpost.com/business/econom y/senate-report-criticizes-hsbc-for-moneylaundering-inadequate- $>$.

DOJ. (2012). HSBC Holdings Plc. and HSBC Bank USA N.A. Admit to Anti-Money Laundering and Sanctions Violations, Forfeit \$1.256 Billion in Deferred Prosecution Agreement. (11/12/2012). Department of Justice. Disponivel em: $<$ https://www.justice.gov/opa/pr/hsbc-holdings-plcand-hsbc-bank-usa-na-admit-anti-moneylaundering-and-sanctions-violations $>$.

DOJ. (2017). Foreign Corrupt Practices Act. (3/2/2017). Department of Justice. Disponível em: $<$ https://www.justice.gov/criminal-fraud/foreigncorrupt-practices-act>.

El Pais. (2015). Morre J. Hawilla, delator e réu confesso do Fifagate. (25/05/2015). El Pais Brasil. Disponível em: <https://brasil.elpais.com/brasil/2018/05/25/deport es/1527259385_497316.html>.

Financial Services Authority (2011). https://thejournalofregulation.com/en/article/finan cial-services-authority/

Fitzgibbon, W. (2018) Panama Papers Law Firm Mossack Fonseca Closes Its Doors. (14/03/2018). ICIJ. Disponível em:

https://www.icij.org/investigations/panamapapers/panama-papers-law-firm-mossack-fonsecacloses-doors/>.

Flick, U.(2009). Introdução à Pesquisa Qualitativa. Trad. Joice Elias Costa. 3. Ed. Porto Alegre: Artmed.

Forbes. (2010) The Global 2000. (21/04/2010). Disponível em: < https://www.forbes.com/lists/ 2010/18/global-2000-10_The-Global2000_Rank.html>.

Gallas, D. (2013). Escândalo da Siemens "ensinou empresários alemães a não pagar propina". BBC Brasil. (13/08/2013). Disponível em: http://www.bbc.com/portuguese/noticias/2013/08/ 130812_siemens_escandalo_dg. 
Gallego, C. S. (2018). Panama Papers investigations bring more than $\$ 700$ million back onshore. (27/06/2018). ICIJ. Disponível em: <https://www.icij.org/blog/2018/06/panamapapers-investigations-bring-700-million-backonshore/>.

Global Witness. (2015). Banks and Dirt Money: How The Financial System enables States Looting at a Devastating Human Cost. Disponível em: $<$ https://www.globalwitness.org/en/campaigns/corr uption-and-money-laundering/banks-and-dirtymoney/>.

Hamilton, M. M. (2015). Whistleblower? Thief? Hero? Introducing The Source Of The Data That Shook HSB. (08/02/2015). ICIJ. Disponível em: $<$ https://www.icij.org/investigations/swissleaks/whistleblower-thief-hero-introducing-sourcedata-shook-hsbc/>.

Harding, L. (2017). Azerbaijan Laundromat shows UK is choice of crooks and despots, says Hodge. (19/10/2017). The Guardian. Disponível em: < https://www.theguardian.com/politics/2017/oct/19 /azerbaijan-laundromat-shows-uk-is-choice-ofcrooks-and-despots-says-hodge>.

Harding, L., Hopkins, N., \& Barr, C.(2017). British banks handled vast sums of laundered Russian money. (20/03/2017). The Guardian. Disponível em: <https://www.theguardian.com/world/2017/mar/20 /british-banks-handled-vast-sums-of-launderedrussian-money>.

Hardouin, P. (2017) Too big to fail, too big to jail: restoring liability a lesson from HSBC case. Journal of Financial Crime. 24(4),513-519.

Harvey, J. (2020). Tracking the international proceeds of corruption and the challenges of national boundaries and national agencies: the UK example. Public Money \& Management, 40(5), 360-368.

Heimann, F., \& Boswell, N, Z. (1998). The OECD Convention: Milestone on the Road to Reform. In Transparency International (ed.), New Perspectives on Combating Corruption (Transparency International, Washington), pp. 65-74.
HSBC. (2007). 2006 Annual Report and Accounts. 2007. 454 p. Disponível em: < https://www.hsbc.com/investor-relations/groupresults-and-reporting/group-reportingarchive?period=All\&company=undefined $\&$ region=un defined\&year $=2006>$.

(2013). HSBC Group: Our story. Disponível em: <https://www.hsbc.com/abouthsbc/company-history>.

.(2018) Annual Report and Accounts 2017. $2018 . \quad$ Disponível em: $<$ https://www.hsbc.com/investor-relations/groupresults-and-reporting/annual-report>.

ICIJ. (2016). Giant Leak Of Offshore Financial Records Exposes Global Array Of Crime And Corruption. (03/04/2016). ICIJ. Disponível em: $<$ https://www.icij.org/investigations/panamapapers/20160403-panama-papers-global>.

.(2017). Explore the Panama Papers Key Figures. In: Investigations - The Panama Papers (31/01/2017). ICIJ. Disponível em: https://www.icij.org/investigations/panamapapers/explore-panama-papers-key-figures/.

Lambsdorff, J. G., \& Schulze, G. G. (2015). What Can We Know About Corruption? A Very Short History of Corruption Research and a List of What We Should Aim For. Journal of Economics and Statistics (Jahrbuecher fuer Nationaloekonomie und Statistik), 235(2), 100-114.

Lasslett, K. (2017) Uncovering the transnational networks, organisational techniques and statecorporate ties behind grand corruption: Building an investigative methodology. International Journal for Crime, Justice and Social Democracy, 6(4), 29-54.

Le Monde. (2011). HSBC, origem do ópio. (8/11/2011). Le Monde Diplomatique Brasil. Disponível em: https://diplomatique.org.br/hsbcorigem-do-opio/.

Leigh, D. (2015). HSBC files: HMRC had data on misconduct before bank boss made trade minister. (09/02/2015). The Guardian. Disponível em: <https://www.theguardian.com/business/2015/feb/ 09/hsbc-files-hmrc-data-misconduct-stephen-greentrade-minister>. 
Linstead, S., Maréchal, G., \& Griffin, R. W. (2014). Theorizing and researching the dark side of organization. Organization Studies, 35(2), p. 165-188.

Ming, S. (2018). (1839): China proíbe importação de ópio. Os acontecimentos que marcaram o dia de hoje na História. (18/03/2018) Deutsche Welle. Disponível em: <http://www.dw.com/pt-br/1839china-pro\%C3\%ADbe-importa\%C3\%A7\%C3\%A3o-de\%C3\%B3pio/a-473490?maca=bra-uol-all-1387-xmluols.

Office Of The Comptroller of The Currency. (2010). OCC Issues Cease and Desist Order Against HSBC Bank USA, N.A. (7/10/2010). Disponível em: $<$ https://www.occ.gov/news-issuances/newsreleases/2010/nr-occ-2010-121.html>.

Platt, S. (2017). Capitalismo Criminoso: como as instituições financeiras facilitam o crime. São Paulo: Cultrix.

Permanent Subcommittee On Investigations of United States Senate. (2010). Keeping Foreign Corruption out of the United States: Four Case Histories. (04/02/2010). Disponível em: $<$ https://www.hsgac.senate.gov/subcommittees/inv estigations/hearings/-keeping-foreign-corruptionout-of-the-united-states-four-case-histories>.

Rose-Ackerman, S. (2002). "Grand" corruption and the ethics of global business. Journal of Banking \& Finance. 26(1),1889-1918.

Rushe, D. \& Treanor, J.(2012). HSBC's record $\$ 1.9 \mathrm{bn}$ fine preferable to prosecution, US authorities insist. (11/12/2012). The Guardian. Disponivel em: <https://www.theguardian.com/business/2012/dec/ 11/hsbc-fine-prosecution-money-laundering>. Acesso em: 05 jun. 2018.

Ryle, G. et al. (2015). 100,000 Clients, \$100 Billion: The Swiss Leaks Data. (08/02/2015). ICIJ. Disponível em: https://www.icij.org/investigations/swissleaks/100000-clients-100-billion-swiss-leaks-data/.

Ryle, G. et al. (2015a). About this project. (08/02/2015). ICIJ. Disponível em: https://www.icij.org/investigations/swissleaks/about-project-swiss-leaks/.

Ryle, G. et al. (2015b). Banking Giant HSBC Sheltered Murky Cash Linked To Dictators And Arms
Dealers. Swiss Leaks. ICIJ. (08/02/2015b). Disponível em: <https://www.icij.org/investigations/swissleaks/banking-giant-hsbc-sheltered-murky-cashlinked-dictators-and-arms-dealers/>.

Seabrooke, L., \& Wigan, D. (2017).The governance of global wealth chains. Review of International Political Economy, 24(1),1-29.

S\&P. (2017).The world's 100 largest banks. (11/04/2017). S\&P Global Intelligence. Disponível em:

<http://www.snl.com/web/client?auth=inherit\#new s/article?id=40223698\&cdid=A-40223698-11568>.

Sikka, P. (2010) Smoke and mirrors: Corporate social responsibility and tax avoidance. Accounting Forum, 34(3-4),153-168.

Sikka, P., \& Lehman, G. (2015) The supply-side of corruption and limits to preventing corruption within government procurement and constructing ethical subjects. Critical Perspectives on Accounting, 28(1),62-70.

Smith, E. B., \& Babcock, C. R. (2015). New Law, New Loophole, New Business for Giant Global Bank HSBC. (08/02/2015). ICIJ. Disponível em: $<$ https://www.icij.org/investigations/swissleaks/new-law-new-loophole-new-business-giantglobal-bank-hsbc/>.

Spink, M. J. (2010) As múltiplas faces da pesquisa sobre produção de sentidos no cotidiano. In: Linguagem e produção de sentidos no cotidiano. (Cap. III, p. 38-59). Rio de Janeiro: Centro Edelstein de Pesquisas Sociais.

STAR - Stolen Asset Recovery Iniciative. (2009). World Bank/ United Nations Office on Drugs and Crime. Washington, DC. Disponível em: <http://siteresources.worldbank.org/EXTSARI/Resou rces/5570284-1257172052492/PEPs-

ful.pdf?resourceurlname=PEPs-ful.pdf $>$.

(2011)The Puppet Masters: How the Corrupt use Legal Structures to Hide Stolen Assets and What to Do about It. World Bank/United Nations Office on Drugs and Crime. Washington, DC. Disponível em: https://star.worldbank.org/star/sites/star/files/pupp etmastersv1.pdf>. 
Sung, H. (2005). Between demand and supply: Bribery in international trade. Crime, law and Social Change, 44(1),111-132.

Sung, H. (2009). Transnational Corruption in Weapons Procurement in East Asia: A Case Analysis. Sociological focus, 42(3),254-275.

Tenbrunsel, A., \& Thomas, J. (2015).The Street, The Bull and The Crisis: United States \& United Kingdom Financial Services Industry Survey. The University of Notre Dame and Labaton Sucharow LLP. Labaton Sucharow. May 2015. Disponível em: <https://www.secwhistlebloweradvocate.com/pdf/L abaton-2015-Survey-report_12.pdf>.

Tax Justice Network. (2018).Tax Havens. Disponível em: <https://www.taxjustice.net/faq/taxhavens/>.

Transparency International (2018). Corruption Perceptions Index 2017. Disponível em: <https://www.transparency.org/news/feature/corru ption_perceptions_index_2017>.
Treanor, J. (2014). Foreign exchange fines: banks handed $f 2.6 \mathrm{bn}$ in penalties for market rigging. (12/11/2014). The Guardian. Disponível em: <https://www.theguardian.com/business/2014/nov/ 12/foreign-exchange-fines-ubs-hsbc-citibank-jpmorgan-rbs-penalties-market-rigging $>$.

U.S. House Of Representative. (2016). Too Big to Jail: Inside the Obama Justice Departament's Decision not to hold Wall Street Accountable. Report Prepared by The Republican Staff of the Committee on Financial Services. Disponível em: < https://financialservices.house.gov/uploadedfiles/07 072016_oi_tbtj_sr.pdf>

Ware, G. T., \& Noone, G. P.(2005). The Anatomy of Transnational Corruption. International Affairs Review, 14(2),29-51.

4IMN. (2017) Newspaper Web Rankings: Top 200 Newspapers in the World. 4 International Media \& Newspapers. Disponível em: $<$ https://www.4imn.com/top200/>.

\section{SOBRE OS AUTORES}

Cintia Rodrigues de Oliveira - Universidade Federal de Uberlândia - UFU, Uberlândia, Minas Gerais, (Brasil). Email: cintia@ufu.br Orcid id: https://orcid.org/0000-0001-7999-9002

Isabella Chaves do Nascimento - Universidade Federal de Uberlândia - UFU, Uberlândia, Minas Gerais, (Brasil). Email: cintiarom@uol.com.br Orcid id: https://orcid.org/0000-0002-4177-3208 


\title{
ANATOMY OF TRANSNATIONAL CORRUPTION: UNRAVELING THE WEBS AND TRAILS OF DIRTY MONEY IN LEGITIMATE BUSINESSES
}

\author{
Cintia Rodrigues de Oliveira e Isabella Chaves do Nascimento \\ Universidade Federal de Uberlândia - UFU, Uberlândia, Minas Gerais, (Brasil)
}

ARTICLE DETAILS
Article history:
Received: 09 April 2020
Accepted: 30 November 2020
Available online January: 01 th 2021
Double Blind Review System
Scientific Editor
Ilan Avrichir

\section{Keywords}

Transnational Corruption

Banks

Crime

\begin{abstract}
Objective: To examine transnational corruption based on empirical analyzes collected from the banking sector, more specific, from one of the largest international banks, HSBC.
\end{abstract}

Method: Qualitative research, documentary type, with an analysis of reports, from the last ten years, on cases of corruption involving the largest international banks in the world. Use open coding by the thematic model.

Main results - The results pointed to trails of corruption, such as networks of actors and actors and corruption schemes.

Relevance / originality - Corruption is a current and relevant topic, however, most analyzes consider the demand side and do not offer supply equivalent to global corruption. In addition, this research addresses corruption as a transnational and not a local phenomenon.

Theoretical / methodological contributions: Necessary - This study was applied by the theoretical-methodological approach, addressing a phenomenon in an international context, whose access to data is an obstacle, as it is unlikely that schemes and operations among corrupt officials are amenable to public activity unless the cases are reported in the press or are under investigation.

Social / management contributions: The research helps business managers with local and international reach, to understand more broadly the consequences of involvement in dangerous operations and connections. 


\section{ANATOMÍA DE LA CORRUPCIÓN TRANSNACIONAL: DESENTRAÑANDO LAS REDES Y LOS RASTROS DE DINERO SUCIO EM NEGOCIOS LEGITIMOS}

Cintia Rodrigues de Oliveira e Isabella Chaves do Nascimento

Universidade Federal de Uberlândia - UFU, Uberlândia, Minas Gerais, (Brasil)

\section{HISTORIA DEL ARTÍCULO}

\section{Historia del Artículo:}

Recibido: 9 de Abril de 2020

Aceptado: 30 de Noviembre de 2020

Disponible en línea: 01 de Enero 2021

Double Blind Review System

Editor Científico

Ilan Avrichir

\section{Palabras-clave:}

Corrupción Transnacional

Banco

Crimen

\section{RESUMEN}

Objetivo: examinar la corrupción transnacional con base en observaciones empíricas recopiladas del sector bancario, más específicamente, de uno de los mayores bancos internacionales, HSBC.

Método: Investigación cualitativa, de tipo documental, con el análisis de informes, de los últimos diez años, sobre casos de corrupción en uno de los bancos internacionales más grandes del mundo. Se utilizó codificación abierta por el modelo temático.

Resultados principales: los resultados apuntan a los rastros de corrupción, las redes de actores y partes interesadas, y los esquemas de corrupción.

Relevancia / originalidad: la corrupción es un tema actual y relevante, sin embargo, la mayoría de los análisis consideran el lado de la demanda, no el lado de la oferta en la ecuación de corrupción global. Además, esta investigación aborda la corrupción como un fenómeno transnacional más que local.

Contribuciones teóricas / metodológicas: necesarias: este estudio contribuye mediante el enfoque teórico-metodológico, ya que aborda un fenómeno en un contexto internacional, cuyo acceso a los datos es un obstáculo, ya que es poco probable que los esquemas y operaciones entre funcionarios corruptos puedan ser expuestos públicamente. a menos que los casos estén expuestos en la prensa o estén bajo investigación.

Contribuciones sociales / de gestión (opcional): la encuesta ayuda a los gerentes de empresas con alcance local e internacional a tener una comprensión más amplia de las consecuencias de la participación en operaciones y conexiones peligrosas.

\section{Como citar este artigo:}

Oliveira, C., \& Nascimento, I. (2021). Anatomia da Corrupção Transnacional: Desvendando as Teias e Trilhas do Dinheiro Sujo em Negócios Legítimos. Internext, 16(1), 89-109. doi: http://dx.doi.org/10.18568/internext.v16i1.603 